\title{
Prevalence of invasive ability and other virulence- associated characteristics in Providencia alcalifaciens strains isolated in São Paulo, Brazil
}

\author{
BEATRIZ E. C. GUTH and E. PERRELLA \\ Department of Microbiology, Immunology and Parasitology, Universidade Federal de São Paulo, Escola \\ Paulista de Medicina, São Paulo, SP, Brazil
}

\begin{abstract}
Providencia alcalifaciens is an invasive enteric pathogen. The present study determined the prevalence of invasive ability in P. alcalifaciens strains isolated in São Paulo, Brazil, mainly from patients with diarrhoea. Invasion of HeLa cells was found in $17(42 \%)$ of 41 strains studied. Most $(\mathbf{8 8} \%)$ of the invasive strains were isolated from diarrhoeal stools. The invasive property was identified in $50 \%$ of $P$. alcalifaciens strains isolated as pure cultures or from stool samples where no other enteropathogen was identified. All the invasive strains caused actin condensation in infected cells. Plasmid profile analysis showed the presence of plasmids of $35.8-180 \mathrm{~kb}$ in $70 \%$ of the strains regardless of their invasive ability, suggesting that invasiveness in $P$. alcalifaciens is not plasmid related. No homology with a probe for gene sequences for invasion of enteroinvasive Escherichia coli and Shigella strains was identified in colony hybridisation assays. The invasive property of $\boldsymbol{P}$. alcalifaciens was confirmed in the present study, but this characteristic did not predominate among strains isolated from patients with diarrhoea in São Paulo City. The presence of other virulence mechanisms and the role of non-invasive $P$. alcalifaciens strains as a cause of diarrhoea remain to be established.
\end{abstract}

\section{Introduction}

The possible role of Providencia alcalifaciens as an aetiological agent of diarrhoea in man was suggested several years ago [1-3]. Providencia spp. have been isolated - usually as the main organism or as pure cultures - from the diarrhoeal stools of patients, particularly children, in the absence of other recognised enteropathogens [4]. While studying travellers' diarrhoea, Haynes and Hawkey [5] found an increased frequency of $P$. alcalifaciens strains in patients who had travelled abroad, suggesting that they might be a major cause of diarrhoea among British travellers.

Invasion was first suggested as the virulence mechanism of $P$. alcalifaciens by Albert et al. [6], who showed that two of three $P$. alcalifaciens isolates from patients with diarrhoea were invasive to HEp-2 cells, producing actin condensation. Later, this observation was extended with another 14 strains from diarrhoeal

Received 26 March 1996; accepted 23 May 1996.

Corresponding author: Dr B. E. C. Guth. stools, suggesting that invasiveness is a property commonly found among $P$. alcalifaciens strains [7]. Invasion of cells by $P$. alcalifaciens has also been detected in rabbit intestinal tissues by electron microscopy [8].

The purpose of this study was to investigate the prevalence of invasive ability among $P$. alcalifaciens strains isolated mainly from patients with diarrhoea in São Paulo, Brazil. Data from the isolates on their ability to promote actin condensation, their plasmid profile, and on tests for their homology with invasion gene sequences of enteroinvasive Escherichia coli and Shigella spp. are also presented.

\section{Materials and methods}

\section{Bacterial strains}

Forty-one $P$ alcalifaciens strains isolated from 35 diarrhoeic and six non-diarrhoeal stools, between 1987 and 1990 in São Paulo were studied. Fifteen of the strains were isolated at a private laboratory from adults and children with diarrhoea and were kindly supplied 
by $\operatorname{Dr}$ L. R. Trabulsi. The remaining strains were isolated at Escola Paulista de Medicina (EPM); 16 of them featured in a project on the aetiology of diarrhoea in children, conducted with the Centers for Disease Control and Prevention (CDC), Atlanta, GA, USA [9]. All the strains were identified biochemically [10] and confirmed as $P$. alcalifaciens as described by Farmer et al. [11]. Among the 41 strains studied, at least eight were isolated as pure cultures and 16 were isolated from stool samples in which no other recognised enteropathogen (such as Shigella, Salmonella, Yersinia, Aeromonas, Campylobacter, enteropathogenic Escherichia coli, enteroinvasive $E$. coli, enterotoxigenic $E$. coli, E. coli $\mathrm{O} 157: \mathrm{H} 7$ or rotavirus) was found; seven strains were associated with another known pathogenic bacterial species or rotavirus and no data were available for the remaining strains.

\section{HeLa cell invasion assay}

Invasion assays were performed as described by Marques et al. [12] except that bacteria were grown overnight in Tryptic Soy Broth (TSB; Difco) and that a suspension of $3.0 \times 10^{8} \mathrm{cfu} / \mathrm{ml}$ was prepared and diluted 1 in 10 in Eagle's Minimal Essential Medium (MEM; Gibco) supplemented with fetal bovine serum (FBS) $10 \%$ and D-mannose $2 \%$. After incubation for $3 \mathrm{~h}$ at $37^{\circ} \mathrm{C}$, bacterial suspensions were removed, the cell monolayers were washed with phosphate-buffered saline (PBS, $\mathrm{pH} \mathrm{7.3)} \mathrm{and} \mathrm{were} \mathrm{then} \mathrm{re-incubated} \mathrm{for} 3 \mathrm{~h}$ in fresh MEM-FBS containing gentamicin $100 \mathrm{mg} / \mathrm{L}$. The monolayers were then washed with PBS, fixed with methanol, stained with May Grünwald followed by Giemsa, mounted on slides, and examined by light microscopy. Invasive $E$. coli strain $9-82:: \operatorname{Tn} 5$ of serogroup O28ac [13] and non-invasive $E$. coli strain C600K 12 were used as controls. To determine the number of intracellular bacteria after gentamicin treatment, the monolayers were washed three times with PBS and then incubated with $0.4 \mathrm{ml}$ of Triton$\mathrm{X} 1001 \%$ for $5 \mathrm{~min}$ at room temperature [14]. Different dilutions of the lysed monolayers in saline $(\mathrm{NaCl}$ $0.85 \%$ ) were plated on MacConkey agar and incubated at $37^{\circ} \mathrm{C}$ for $18 \mathrm{~h}$. Experiments were run in duplicate and repeated twice for each isolate. The susceptibility of all $41 P$. alcalifaciens strains studied to gentamicin was previously confirmed by standard methods [15] (data not shown).

\section{Fluorescent actin staining (FAS) test}

All invasive and 10 non-invasive strains were tested for actin condensation with HeLa cell monolayers in 6-h assays as described previously [16]. The control strains were those used in invasion assays.

\section{Plasmid DNA anaylsis}

Plasmid DNA was prepared by the method of Birnboim and Doly [17] and examined by electrophoresis in agarose $0.8 \%$ slab gels. Plasmid sizes were determined by comparison of their relative migration rates with those of plasmids of known size $(147,63,35.8$ and $6.9 \mathrm{~kb}$ ) present in E. coli K12 strain NCTC 39R861.

\section{Colony hybridisation}

The presence of genes associated with invasiveness of enteroinvasive E. coli (INV) and Shigella spp. was tested by colony hybridisation assays [18] with the $2.5-\mathrm{kb}$ HindIII fragment from plasmid pSF55 as a probe [19]. The E. coli $\mathrm{K} 12$ strain harbouring pSF55 and the invasive $E$. coli $\mathrm{O} 28 \mathrm{ac}$ strain [13] were used as positive controls, and $E$. coli strain K12 containing pBR322 [19] was used as a negative control.

\section{Results}

Invasion of HeLa cells was observed in $17(42 \%)$ of the $41 P$. alcalifaciens strains. However, of the $24 P$. alcalifaciens strains found in faeces either as a pure culture or when no other enteropathogens were present, $12(50 \%)$ were identified as invasive strains.

The origin and characteristics of the invasive strains studied are shown in Table 1. Most (15 of 17 strains) were isolated from diarrhoeal stools. In the invasion assay, the number of intracellular bacteria varied from $4.0 \times 10^{3}$ to $1.8 \times 10^{5} \mathrm{cfu} / \mathrm{ml}$, while the invasive and negative controls used yielded $4.2 \times 10^{5}$ and $0 \mathrm{cfu} / \mathrm{ml}$ respectively. No colonies were recovered from the MacConkey plates of the non-invasive strains. All the invasive strains promoted actin condensation as shown by the FAS test, and none of the non-invasive strains caused actin condensation.

Plasmid profile analysis showed the presence of plasmids ranging from 180 to $35.8 \mathrm{~kb}$ in 29 of the $41 P$. alcalifaciens strains. Of the 17 invasive strains, nine did not harbour a plasmid, seven harboured one plasmid, and one harboured three plasmids. The plasmids of the invasive strains varied in size, although some of them were of similar mol.wt (Table 1).

Under the conditions used, none of the $41 P$. alcalifaciens strains studied showed hybridisation with the INV probe when compared to the results of the invasive positive control.

\section{Discussion}

Invasion of cells by $P$ alcalifaciens was demonstrated originally by Albert et al. [6,7] in the HEp-2 cell assay. In the present study, the invasive ability of $P$. alcalifaciens strains was evaluated in HeLa cells. Fortytwo percent of $P$. alcalifaciens strains were found to be invasive and no differences in invasive ability were 
Table 1. Origin and characteristics of invasive $P$. alcalifaciens strains

\begin{tabular}{|c|c|c|c|c|c|c|}
\hline \multirow[b]{2}{*}{ Strain no. } & \multicolumn{3}{|c|}{ Patient data } & \multirow{2}{*}{$\begin{array}{c}\text { Intracellular } \\
\text { bacteria }^{\ddagger} \\
(\mathrm{cfu} / \mathrm{ml})\end{array}$} & \multirow{2}{*}{$\begin{array}{l}\text { FAS } \\
\text { test }\end{array}$} & \multirow{2}{*}{$\begin{array}{c}\text { Presence of } \\
\text { plasmids } \\
\text { (size in kb) }\end{array}$} \\
\hline & Age & Diarrhoea & Other pathogen isolated ${ }^{\dagger}$ & & & \\
\hline $0351-6$ & 4 years & Yes & Rotavirus & $4.0 \times 10^{3}$ & + & - \\
\hline $681-8$ & 1 year 2 months & Yes & ETEC & $1.0 \times 10^{5}$ & + & $90,63,50$ \\
\hline $762-8$ & 2 years 3 months & No & - & $1.2 \times 10^{4}$ & + & - \\
\hline $2401-2$ & 4 years 11 months & Yes & EIEC & $5.6 \times 10^{4}$ & + & - . \\
\hline $3761-8$ & 2 years 2 months & Yes & A. caviae & $1.8 \times 10^{5}$ & + & 50 \\
\hline $4002-10$ & 1 year 8 months & No & - & $4.1 \times 10^{4}$ & + & 45 \\
\hline P-56 & Child $^{*}$ & Yes & ND & $2.1 \times 10^{4}$ & + & 35.8 \\
\hline 40448 & 2 years & Yes & $P$ & $2.2 \times 10^{4}$ & + & 54 \\
\hline P-40 & Child* $^{*}$ & Yes & $\mathbf{P}$ & $1.0 \times 10^{5}$ & + & 72 \\
\hline $9045-3$ & Child $^{*}$ & Yes & $P$ & $1.4 \times 10^{5}$ & + & 180 \\
\hline 47176 & 3 years 5 months & Yes & - & $1.6 \times 10^{4}$ & + & - \\
\hline 9400 & 11 months & Yes & - & $2.0 \times 10^{4}$ & + & - \\
\hline $4631-10$ & Child* & Yes & - & $4.8 \times 10^{4}$ & + & - \\
\hline 52713 & 1 year 8 months & Yes & - & $3.1 \times 10^{4}$ & + & - \\
\hline 65473 & 4 months & Yes & $P$ & $7.0 \times 10^{4}$ & + & - \\
\hline 66878 & 8 months & Yes & - & $3.4 \times 10^{4}$ & + & - \\
\hline 9938 & 32 years & Yes & $P$ & $4.0 \times 10^{3}$ & + & 63 \\
\hline
\end{tabular}

*Child: age data not available.

${ }_{-}$, no pathogen identified; $\mathrm{P}$, pure culture; ND, data not available; ETEC, enterotoxigenic E. coli; EIEC, enteroinvasive E. coli.

${ }^{\ddagger}$ Values are averages of duplicate assays; the invasive control strain showed $4.2 \times 10^{5} \mathrm{cfu} / \mathrm{ml}$ and non-invasive $\mathrm{K} 12 E$. coli showed $0 \mathrm{cfu} / \mathrm{ml}$.

found when HEp-2 cells were used instead of HeLa cells (data not shown). Except for two strains, all the invasive $P$. alcalifaciens strains identified were isolated from patients with diarrhoea. A higher frequency of invasive ability (from $42 \%$ to $50 \%$ ) was observed if only the $P$. alcalifaciens strains isolated from stools as pure culture or when no other recognised enteropathogen was identified were considered.

Although a high frequency of invasiveness was found among these $P$. alcalifaciens strains isolated in São Paulo City, almost half of them did not present this virulence trait. These results contrast with those of other studies $[6,7]$, in which all $P$. alcalifaciens isolates from diarrhoeal stools in Bangladesh were invasive. However, in support of Albert et al. [6], no other virulence factor such as the production of enterotoxins and cytotoxins was detected in any of the $P$. alcalifaciens strains studied (data not shown).

On the other hand, it is possible that the invasive and non-invasive $P$. alcalifaciens strains isolated in São Paulo may belong to different subgroups or biotypes. Preliminary results show that the invasive and noninvasive strains are of different ribotypes, thus suggesting the presence of distinct clones among the strains studied (unpublished observation).

Cell invasiveness is plasmid related in some classical invasive enterobacteria such as Shigella spp. [20], enteroinvasive $E$. coli $[21,22]$ and $Y$. enterocolitica [23]. Therefore, the loss of these elements could be responsible for lack of expression of such property. However, this seems not to be the case for the $P$. alcalifaciens strains studied, because plasmids were not found in nine of the 17 invasive strains. These results suggest that the ability of $P$. alcalifaciens strains to invade HeLa cells is not plasmid related. Similar observations have been described for invasive strains of Edwardsiella tarda [12].

All the invasive $P$. alcalifaciens strains studied caused polymerisation of actin filaments demonstrated by the FAS test, confirming previous work $[6,7]$.

Some analogies between invasion of $P$. alcalifaciens and Shigella spp. have been suggested. These bacteria presented similar patterns of actin condensation [6] and their invasion processes were inhibited by cytochalasin D, a microfilament inhibitor [7]. Moreover, both organisms required prior growth at $37^{\circ} \mathrm{C}$ for optimal expression of the invasive phenotype.

Colony hybridisation assays with the INV probe pSF55 [19] were performed to determine if the gene sequences for invasion of enteroinvasive $E$. coli and Shigella spp. could be used to identify invasive $P$. alcalifaciens strains. Although the specific genes present on this probe are not known, Wood et al [24] and Gomes et al. [25] showed that this sequence presented $100 \%$ sensitivity in detecting both Shigella and enteroinvasive $E$. coli Serèny-test positive strains, and was able to identify some Serèny-negative $E$. coli strains that retained their ability to invade HeLa cells. No hybridisation with the INV probe was observed with any of the strains in the present study, suggesting that the genome of $P$. alcalifaciens shares no homoloy with the invasion gene sequences of those bacteria. In this respect, it is like that of invasive Salmonella spp. [24].

Although the invasive property of $P$ alcalifaciens was confirmed, this virulence characteristic did not predominate among the strains isolated from patients with diarrhoea in São Paulo City, Brazil. The possible 
presence of other virulence determinants and the role of non-invasive $P$. alcalifaciens strains as the aetiological agents of diarrhoea remain to be established. Animal models should be developed to assess the pathogenic potential of the non-invasive strains isolated in this study. Moreover, further epidemiological case-control studies in different geographical areas are required to help elucidate the role $P$. alcalifaciens strains play in diarrhoeal disease.

This work was supported by Conselho Nacional de Desenvolvimento Científico e Tecnológico $(\mathrm{CNPq})$ and Coordenadoria e Aperfeiçoamento de Pessoal de Nivel Superior (CAPES). We thank Dr L. R. Trabulsi for providing some of the strains studied, Sandra $\mathrm{H}$. Fabbricotti and Monica A. M. Vieira for their technical assistance, and $\mathrm{Dr}$ T. A. T. Gomes for critically reviewing the manuscript.

\section{References}

1. Bhat P, Myers RM, Feldman RA. Providence group of organisms in the aetiology of juvenile diarrhoea. Indian $J$ Med Res 1971; 59: 1010-1018.

2. Graber CD, Lincoln AF. Infantile diarrhoea in the Denver area: significance of Proteus-Providencia organisms. Pediatrics 1955; 16: 585-589.

3. Stuart CA, Wheeler KM, McGann V. Further studies on one anaerogenic paracolon organism, type 29911. J Bacteriol 1946; 52: $431-438$.

4. Sen R. Isolation of strains of the Providence group from cases with diarrhoea in Ibadan, Nigeria, West Africa. Indian $J$ Med Res 1962; 50: 622-626

5. Haynes J, Hawkey PM. Providencia alcalifaciens and travellers' diarrhoea. BMJ 1989; 299: 94-95.

6. Albert MJ, Alam K, Ansaruzzaman M et al. Pathogenesis of Providencia alcalifaciens-induced diarrhea. Infect Immun 1992; 60: $5017-5024$

7. Albert MJ, Ansaruzzaman M, Bhuiyan NA, Neogi PBK, Faruque ASG. Characteristics of invasion of HEp-2 cells by Providencia alcalifaciens. $J$ Med Microbiol 1995; 42: 186-190.

8. Mathan MM, Mathan VI, Albert MJ. Electron microscopic study of the attachment and penetration of rabbit intestinal epithelium by Providencia alcalifaciens. J Pathol 1993; 171: 67-71.

9. Gomes TAT, Ramos SRTS, Rodrigues D et al. Etiology of acute diarrhea in children 1 to 5 years old in São Paulo, Brazil. In: Abstracts of the 94th General Meeting of the American Society for Microbiology. Las Vegas, Nevada. 1994: 543.

10. Ewing WH. The tribe Proteceae. In: Edwards and Ewing's identification of Enterobacteriaceae, 4th edn. New York, Elsevier Science Publishing. 1986: 443-459.

11. Farmer JJ, Davis BR, Hickman-Brenner FW et al. Biochemical identification of new species and biogroups of Enterobacteriaceae isolated from clinical specimens. $J$ Clin Microbiol 1985; 21: 46-76.

12. Marques LRM, Toledo MRF, Silva NP, Magalhäes M, Trabulsi LR. Invasion of HeLa cells by Edwardsiella tarda. Curr Microbiol 1984; 10: 129-132.

13. Silva RM, Saadi S, Maas WK. A basic replicon of virulenceassociated plasmids of Shigella spp. and enteroinvasive Escherichia coli is homologous with a basic replicon in plasmids of IncF groups. Infect Immun 1988; 56: 836-842.

14. Small PLC, Isberg RR, Falkow S. Comparison of the ability of enteroinvasive Escherichia coli, Salmonella typhimurium, Yersinia pseudotuberculosis, and Yersinia enterocolitica to enter and replicate within HEp-2 cells. Infect Immun 1987; 55: $1674-1679$.

15. Bauer A, Kirby WMM, Sherris JC, Turck M. Antibiotic susceptibility testing by a standardized single disk method. $\mathrm{Am}$ $J$ Clin Pathol 1966; 45: 493-496.

16. Knutton S, Baldwin T, Williams PH, McNeish AS. Actin accumulation at sites of bacterial adhesion to tissue culture cells: basis of a new diagnostic test for enteropathogenic and enterohemorrhagic Escherichia coli. Infect Immun 1989; 57: 1290-1298.

17. Birnboim HC, Doly J. A rapid alkaline extraction procedure for screening recombinant plasmid DNA. Nucleic Acids Res 1979; 7: 1513-1523.

18. Maas R. An improved colony hybridization method with significantly increased sensitivity for detection of single genes. Plasmid 1983; 10: 296-298.

19. Small PLC, Falkow S. Development of a DNA probe for the virulence plasmid of Shigella spp. and enteroinvasive Escherichia coli. In: Leive L (ed) Microbiology. Washington, DC, American Society for Microbiology. 1986: 121-124.

20. Sansonetti PJ, Kopecko DJ, Formal SB. Involvement of a plasmid in the invasive ability of Shigella flexneri. Infect Immun 1982; 35: 852-860.

21. Silva RM, Toledo MRF, Trabulsi LR. Correlation of invasiveness with plasmid in enteroinvasive strains of Escherichia coli. J Infect Dis 1982; 146: 706.

22. Harris JR, Wachsmuth IK, Davis BR, Cohen ML. Highmolecular-weight plasmid correlates with Escherichia coli enteroinvasiveness. Infect Immun 1982; 37: 1295-1298.

23. Zink DL, Feeley JC, Wells JG et al. Plasmid-mediated tissue invasiveness in Yersinia enterocolitica. Nature 1980; 283: 224-226.

24. Wood PK, Morris JG, Small PLC et al. Comparison of DNA probes and the Sereny Test for identification of invasive Shigella and Escherichia coli strains. J Clin Microbiol 1986; 24: 498-500.

25. Gomes TAT, Toledo MRF, Trabulsi LR, Wood PK, Morris JG. DNA probes for identification of enteroinvasive Escherichia coli. J Clin Microbiol 1987; 25: 2025-2027. 